\title{
Predicting Population Status of Gum and Resin Bearing Plant Species from Size Distributions in Benishangul Gumuz Regional State, Ethiopia: Inferences for Their Sustainable Management
}

Dereje Mosissa (Corresponding Author)

Ethiopian Biodiversity Institute, Assosa Biodiversity Center, P.O. Box 98, Assosa, Ethiopia

Email: derament5964@gmail.com

\section{Girum Faris}

Ethiopian Biodiversity Institute, Genetic Resources Access and Benefit Sharing Directorate, Addis Ababa, Ethiopia

\section{Sisay Aman}

Assosa University, Department of Geography \& Environmental Studies, College of Agriculture, Assosa, Ethiopia

\author{
Article History \\ Received: 9 July, 2021 \\ Revised: 16 August, 2021 \\ Accepted: 23 August, 2021 \\ Published: 28 August, 2021 \\ Copyright (C) 2021 ARPG \& \\ Author \\ This work is licensed under \\ the Creative Commons \\ Attribution International

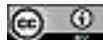 \\ CC BY: Creative \\ Commons Attribution \\ License 4.0
}

\begin{abstract}
Diversity, population structures, and regeneration status of gum- and resin-producing woody species, were assessed in 116 sample plots, each measuring $400 \mathrm{~m} 2$ and established along line transects. The data were collected in two selected districts, namely, Sherkole and Kurmuk in Benishangul-Gumuz National Regional State, one of the gums and resin belts in western Ethiopia. The gum- and resin-producing woody species had 1.04 and 0.7 diversity and 0.576 and 0.49 evenness values at Kurmuk and Sherkole districts, respectively. They accounted for $26 \%$ and $46 \%$ of the density, $51 \%$ and $58 \%$ of the basal area, and $32 \%$ and $53 \%$ of the Importance Value Index of all the woody species, respectively. The gum- and resin-bearing woody species exhibited three patterns of population structure. The first pattern suggests good reproduction abilities of the species coupled with a good recruitment of seedlings and their subsequent continuous growth to replace older individuals over time, indicating stable regeneration. About $61 \%$ of the gum- and resin-bearing woody species fall under this category. The other two patterns indicate the hampered regeneration status of the woody species. Heavy grazing, conversion to cropland by small-scale farming, gold mining, recurrent fire, and climate change were mentioned as major bottlenecks of natural regeneration and recruitment. Policy, extension, and research recommendations are discussed.
\end{abstract}

Keywords: Density; Diversity; Evenness; Frequency; Gum and resin; Importance value index; Population structure; Regeneration.

\section{Introduction}

Ethiopia owns one of the extensive forest vegetation resources in the Horn of Africa. Ethiopia's forest vegetation resources are classified into six broad categories, namely, forestlands, woodlands, shrublands, bushlands, plantations and bamboos [1]. Together, these forest vegetation resources cover some $50 \%$ of the 1.12 million $\mathrm{km}^{2}$ total landmass of the country. The share of high forest, however, is only $3.5 \%$ whereas, woodland, shrubland and bushland combined contribute about $45 \%$ of the landmass, indicating that the latter cover quite extensive areas and ecosystems [2]. Recent studies [3], re-grouped the vegetation resources of Ethiopia into 12 types.

Seven of these vegetation types are encountered in drier lowland areas of the country and are commonly referred to as dry forests [4]. Combretum-Terminalia, broad-leaved deciduous dry forests and Acacia-Commiphora, smallleaved woodlands, are the two most prominent dry forest vegetation resources in the lowlands, both socioeconomically and ecologically $[5,6]$.

The current study targeted the Combretum-Terminalia woodland in the northwestern lowlands of the country. According to Awas [7], the Combretum-Terminalia vegetation is distributed in the northern, northwestern, western, southwestern and central parts of Ethiopia. The Combretum-Terminalia forest formations are key ecological components of several major landscapes of Ethiopia, including the Blue Nile River Basin, and support unique native biodiversity [7, 8]. These forest resources are known to harbour diverse high-value woody species, such as those that produce commercial gums and resins [4,5]. In Ethiopia, 21 Commiphora, 6 Boswellia, 12 Acacia and 3 Sterculia species have been identified so far as major sources and/or adulterants of commercial gums and resins [5, 9-11].

Major gums and resins of international commerce produced and traded in and from Ethiopia include frankincense from various Boswellia species; gum Arabic, gum gumero and gum talha from Acacia species; and myrrh, opopanax and hagar from Commiphora species [9]. In addition, recent studies (e.g. [5, 11, 12] reported existing opportunities to produce trade volume of gum karaya from Sterculia species in different parts of the country. Professional estimates show that Ethiopia has over 3.5 million ha of woodlands and bushlands with an estimated annual production potential of 270,000 tons of gums and resins [4]. 
Despite the diverse woody species harbored by the Combretum-Terminalia and Acacia-Commiphora vegetation resources and their huge socio-economic and ecological importance, these resources are under increasing anthropogenic and natural pressures $[8,12,13]$. This has resulted in severe degradation of habitats, soil and water resources as well as decline of biodiversity in the drylands of the country where these resources are common. According to Lemenih and Kassa [4], until recently very little attention has been given to develop, protect and sustainably manage these valuable resources. Instead, Rahmato [14] argued that there is a massive transformation of forestland into farmlands in the Combretum-Terminalia woodland belt, ignoring the various socio-economic and ecological benefits that can be obtained through sustainable management and conservation of the forest vegetation. Experts, thus, worry that such massive conversion of forestland to other land uses might lead to irreversible damage to these ecosystems.

Various current professional discussions indicate that the growing pressure on dry forest resources is partly due to inadequate or, in some cases, complete lack of comprehensive scientific information and knowledge on the status of current stock and dynamics of the plant populations housed in these vegetation resources. A good example is the Benishangul-Gumuz National Regional State (BGNRS) in western Ethiopia. This region is one of the major frankincense belts of the country. However, little is known about the diversity, abundance, distribution and dynamics of the gum- and resin- bearing and associated woody species in the region. Hence, while concerted efforts of the relevant government and non-government organizations to integrate the currently marginalized forest resources into the overall rural development planning is a key step forward, in-depth scientific investigations on the status of plant populations of these resources are of paramount importance. Apparently, available information suggests that production of non- timber forest products, such as gums and resins, would help to promote a better integration of dry forests and, thereby, enhance economic productivity along with environmental conservation in these fragile ecosystems $[9,10]$.

The objective of this study was to provide empirical information on the diversity, abundance, population structures and status of natural regeneration of gum- and resin-producing woody species in BGNRS. This will contribute to the ongoing efforts of generating basic information nation-wide on the status of dry forests and woodlands and develop suitable management models that can facilitate their integration into the planning process of agricultural development and re-settlement programme in the country.

\section{Materials and Methods}

\subsection{Study Area}

The Benishangul-Gumuz National Regional State shares common borders with the Amhara National Region State in the north and east, the Sudan in the northwest and the Oromia National Region State in the south (Figure 1). It is divided into three administrative zones, namely, Metekel, Kemashi and Assosa, and a total of 19 districts. Metekel is the largest zone with an area of $26,272 \mathrm{~km}^{2}$ followed by Asosa $\left(14,166 \mathrm{~km}^{2}\right)$. The altitude of BGNRS ranges from $600 \mathrm{~m}$ in areas bordering the Sudan to over $2500 \mathrm{~m} \mathrm{[7],} \mathrm{and} \mathrm{about} 75 \%$ of the land is below $1500 \mathrm{~m}$, traditionally referred to as kola (literally 'dry and hot'). The average annual temperatures are between 20 and $258 \mathrm{C}$. During the hottest months (between January and May), they range between 28 and 348C. The annual rainfall ranges between 500 and $1800 \mathrm{~mm}$ and is spread through May to October.

The number of vascular plants in BGNRS is estimated at 1102 species, with 28 of them being endemic to Ethiopia [7]. The forests and woodlands are characterized by small- to moderate-sized trees and shrubs. According to Awas [7], the region is one of the few areas in Ethiopia selected by the Government as development corridor for rain-fed and irrigated commercial farming.

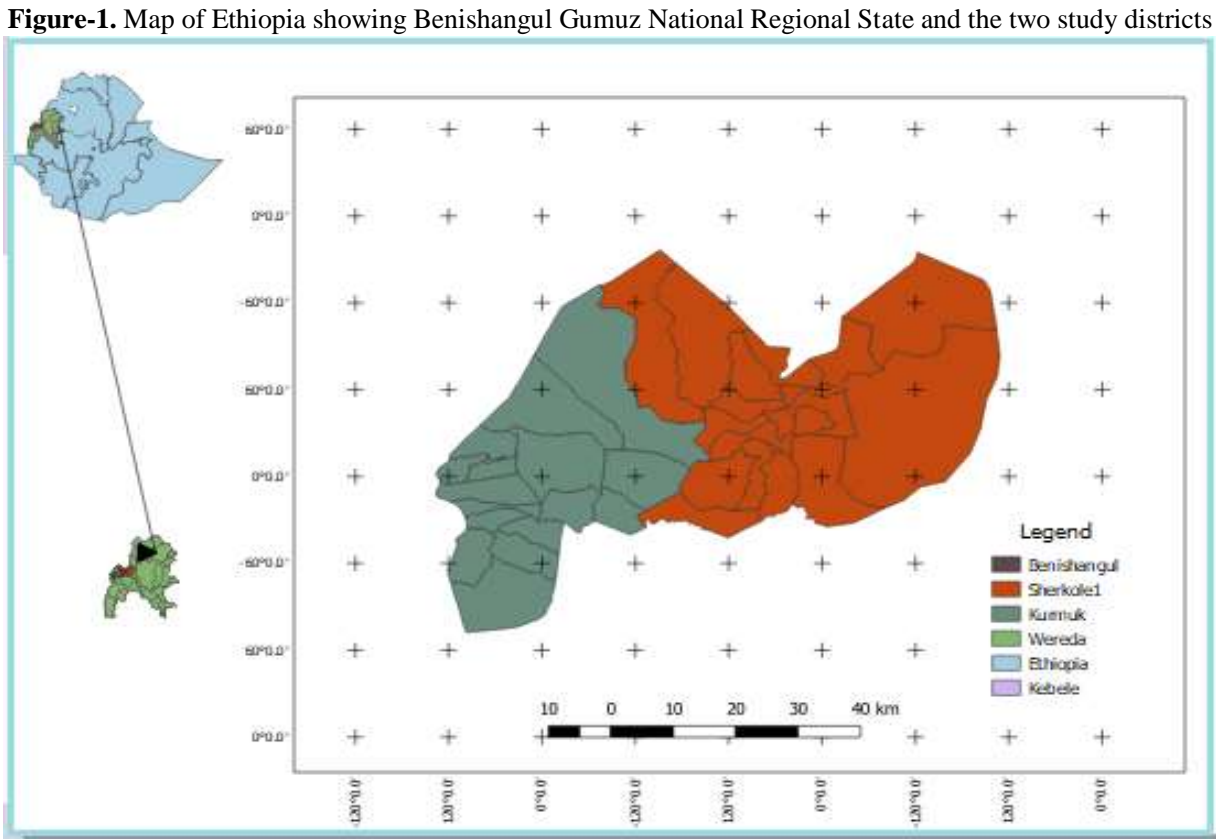


There is a serious concern among professionals and local communities on the effect of such massive agricultural plan that may affect the plant resources and ecosystem functions. According to discussions with local experts and authorities, and despite the acknowledgement of the issues by the Government, there was not enough initiative to minimize the potential anthropogenic impact on the plant communities and the associated landscapes. The human population of the BGNRS was estimated at 670,847 in 2007 [15], of which $90 \%$ live in rural areas, indicating a very low level of urbanization in the region [7]. In addition to the introduction of commercial farming, there is an increase in human and livestock populations in the region that could also lead to additional pressure on the wellbeing of the plant communities and the ecosystem.

The study was carried out in one administrative zones, namely, Assosa. The Berta ethnic group dominate Assosa zone. This zone is known to support extensive dry forest resources that harbour gum- and resin-producing species. Two districts, Sherkole and Kurmuk were randomly selected from the lists of districts in the zone. According to the 2007 national census, the total population of Sherkole was 19,992 with a population density of 7.8 persons per $\mathrm{km}^{2}$ and that of Kurmuk was 14,907 with 3.8 inhabitants per $\mathrm{km}^{2}$ [15]. The altitudes of the two districts range between 500 and $1500 \mathrm{~m}$ asl [1]. According to Awas [7], altitude is the most important environmental gradient determining species distribution in the region. Both districts receive mean annual rainfall ranging between 900 and $1200 \mathrm{~mm}$ and experience six months of dry season. The mean annual temperature ranges between 20 and 27.58C. In each district, a $5 \mathrm{~km}$ x $5 \mathrm{~km}$ site was chosen for data collection. In the following, 'Sherkole' refers to the Sherkole study site, and 'Kurmuk' refers to the Kurmuk study site.

\subsection{Data Collection}

As there is no sufficient vegetation map for the study areas, an ocular boundary demarcation technique was used to approximately delineate the boundaries of the vegetation types [16]. This was carried out based on existing topographic map and the intensive reconnaissance survey carried out to roughly delineate the distribution of the vegetation in the study districts. Additional inputs were also obtained from local experts and knowledgeable rural people. The information from these sources indicated that most parts of the study districts were uniform in terms of the overall vegetation distribution and structure. The study areas house Combretum-Terminalia woodland in which Boswellia and Sterculia species are also found. Further, the topography of most parts of the districts is also uniform. Based on these observations, 21 transects (10 in Sherkole and 11 in Kurmuk), with variable lengths, were laid along a 566 to $1400 \mathrm{~m}$ asl altitudinal gradient. The first transect line was randomly laid and the rest were set at an interval of $500 \mathrm{~m}$ from each other. The variations in the length of transect lines resulted from inaccessibility of some parts of the forest and encountering other land uses, e.g. gold mining and crop farming areas.

A total of $118(20 \mathrm{~m}$ x $20 \mathrm{~m}$ ) sample plots (61 in Kurmuk and 57 in Sherkole) were laid along the transect lines, following the procedures described by Kent and Coker [16]. In each plot, the identity, number of individuals, diameter at breast height (DBH) and height of all woody species having a height above $1.5 \mathrm{~m}$ were recorded. Subplots of $5 \mathrm{mx} 5 \mathrm{~m}$ was used for woody species inventory. Individuals with heights of $1.5 \mathrm{~m}$ were considered as seedlings, counted and recorded [5]. DBH and height were measured using a diameter tape and hypsometer, respectively. In addition, discussions were held with local experts, rural knowledgeable persons and companies engaged in the export of gums and resins to get insights about the status of gum and resin collection and trade in the region in general and at the study zones in particular.

\subsection{Data Analyses}

Diversity of all gum and resin bearing species was determined using the Shannon - Wiener Diversity Index $(\mathrm{H})$ and evenness (E) [16]. Jaccard's Similarity Coefficient $\left(\mathrm{S}_{\mathrm{j}}\right)$ was used to compute similarity in woody species composition of the two districts. The indices were computed using the following formulas:

$$
\mathrm{H}=-\sum_{i=1}^{S} \text { pi ln pi }
$$

where $\mathrm{H}$ is Shannon - Wiener diversity index and $\mathrm{P}_{\mathrm{i}}$ is the proportion of individuals found in the $\mathrm{i}^{\text {th }}$ species;

$$
\mathrm{E}_{\mathrm{H}}=\mathrm{H} / \mathrm{Hmax}=H / \ln S
$$

where $\mathrm{E}$ is evenness, $\mathrm{H}_{\max }$ is the maximum level of diversity possible within a given population, which equals $\ln$ (number of species); and

$$
\mathrm{J}=\frac{\mathrm{C}}{\mathrm{A}+\mathrm{B}+\mathrm{C}}
$$

where $\mathbf{J}$ is Jaccard's similarity coefficient, $\mathrm{C}$ is the number of species common to both sites, A is the number of species present in one of the sites to be compared and B is the number of species present in the other site.

Density was calculated by converting the total number of individuals of each species to equivalent numbers per hectare (absolute density), and as the percentage of the absolute density of each species divided by the total stem number of all species ha ${ }^{21}$ (relative density). Frequency distribution of each species was determined from the number of plots in which the species was recorded (absolute frequency) [16], and as a percentage (relative frequency) by dividing the absolute frequency of the species by the sum of the absolute frequencies of all the species. The absolute dominance of woody species with DBH. $2.5 \mathrm{~cm}$ was determined from summing the basal area (BA) of all individuals of a species. Relative dominance was calculated as the percentage of the BA of a species divided by the total BA of all species.

The relative ecological importance of each woody species, commonly referred to as Important Value Index (IVI), was determined by summing its relative frequency, relative density and relative dominance [16].

The population structures and status of natural regeneration of the entire woody vegetation and that of gum- and resin- bearing woody species was assessed from the frequency distribution of diameters based on histograms 
constructed by grouping all individuals of each woody species into the following successive diameter classes: $1=0$ $-10,2=10-20,3=20-30,4=30-40$ and $5=40 \mathrm{~cm}[17-19]$.

\section{Results}

\subsection{Species Richness}

In total, six species, namely, Acacia seyal, Acacia senegal, Acacia polyacantha, Boswellia papyrifera, Commiphora africana and Sterculia africana were identified as sources of commercial gums and resins. Fabaceae is the families that encompasses the two gum and resin bearing species.

\subsection{Diversity, Evenness and Similarity}

The diversity $(\mathrm{H})$ values of gum- and resin-bearing woody species were 0.46 and 0.86 , respectively.

Table-1. List of gum and resin bearing species encountered in the Kurmuk and Sherkole study plots in descending order of IVI values.

\begin{tabular}{l|l|l|l|l|l|l|l|l}
\hline Scientific name & Family & DE & RDE & DO & RDO & FR & RFR & IVI \\
\hline & & & & & & & & \\
\hline Boswellia papyrifera & Burseraceae & 65 & 10.80 & 8.32 & 45.21 & 55 & 8.58 & 67.00 \\
\hline Acacia polyacantha & Anacardiaceae & 98 & 17.74 & 0.92 & 5.06 & 77 & 11.2 & 35.60 \\
\hline Sterculia africana & Sterculiaceae & 66 & 13.09 & 2.10 & 11.1 & 65 & 10.74 & 35.60 \\
\hline Acacia seyal & Fabaceae & 13 & 3.18 & 1.14 & 0.70 & 28 & 4.29 & 7.28 \\
\hline Acacia senegal & Fabaceae & 11 & 3.02 & 1.09 & 0.04 & 23 & 4.00 & 6.66 \\
\hline Commiphora africana & Burseraceae & 7 & 1.47 & 0.08 & 0.48 & 14 & 2.31 & 4.28 \\
\hline Total & & 260 & 49.3 & 18 & 100 & 606 & 100 & 300 \\
\hline
\end{tabular}

Note: DE $1 / 4$ absolute density $\left(\mathrm{ha}^{21}\right)$, RDE $1 / 4$ relative density (\%), FR $1 / 4$ absolute frequency (\%), RFR $1 / 4$ relative frequency (\%), DO $1 / 4$ absolute dominance $\left(\mathrm{m}^{2}\right)$, RDO $1 / 4$ relative dominance $(\%)$ and IVI $1 / 4$ Importance Value Index

\subsection{Density, Frequency and Dominance}

The densities of gum- and resin-bearing woody species accounted for $29 \%$ and $50 \%$ of the total density values at Sherkole and Kurmuk, respectively. Few of the species dominated the woody vegetation and exhibited higher frequency values. At Sherkole, S. africana and B. papyrifera were the two relatively abundant gum- and resinbearing species (Table 1). However, A. seyal and C. africana were represented with few individuals. Among the gum- and resin-bearing species, A. polyacantha, A. seyal and B. papyrifera showed a relatively abundant representation. In contrast, S. setigera and A. senegal were the least abundant gum- and resin-bearing species.

B. papyrifera and S. africana were the most frequent gum- and resin-bearing species at Sherkole with $66 \%$ and $59 \%$ frequency values, respectively. C. africana and A. seyal were the least frequent gum- and resin-bearing species at Sherkole. At Kurmuk, S. africana (frequency 1/4 35\%), A. polyacantha (frequency $1 / 4$ 33\%) and B. papyrifera (frequency $1 / 4$ 32\%) were relatively the most frequent gum- and resin-bearing species compared with the least frequent species, namely A. senegal (frequency, 11\%) and A. seyal (frequency, 9\%). B. papyrifera, S. africana and A. seyal were common to both sites while C. africana was recorded only in plots at Sherkole, and A. senegal and A. polyacantha only in plots at Kurmuk.

\subsection{Importance Value Index}

The Importance Value Index (IVI) values of all the woody species ranged between 4.28 (C. africana) and 67 (B. papyrifera) at the two districts (Table 1). The gum- and resin-bearing woody species accounted for $37 \%$ and $50 \%$ of the total IVI values at Sherkole and Kurmuk, respectively (Table 1).

\subsection{Population Structure and Status of Natural Regeneration}

The population structures of gum and resin bearing species at both sites exhibited an 'inverted-J' shaped frequency distribution of diameter classes (Figure 2a). In Kurmuk, in particular, the diameter distribution of gumand resin-bearing species showed clear 'inverted-J' shape with larger number of individuals in smaller diameter classes and, to a lesser extent, a decline in abundance in the next diameter classes. However, the contribution of gum- and resin bearing species to the sapling population of the entire woody species was higher at Kurmuk (21\%) compared with Sherkole (13\%), where S. africana, B. papyrifera, A. seyal and C. africana were among the major contributors.

The gum- and resin- bearing woody species can be categorized into three groups based on the patterns exhibited by their population structures. The first group exhibited an inverted ' $\mathrm{J}$ ' shaped population structure, where higher numbers of individuals were observed at the lowest diameter classes and progressively declining numbers of individuals with increasing diameter classes. This pattern of population structure indicates stable or healthy regeneration of the species. Acacia senegal, A. polyacantha, A. seyal and C. africana belonged to this group. The second group represents a bell-shaped diameter distribution demonstrated by B. papyrifera at both study districts. The third type of population structure was a 'J' shaped diameter class frequency distribution exhibited by S. africana in Sherkole district (Figures 2 and 3). In fact, S. africana depicted an inverted 'J' shaped diameter distribution in Sherkole district. In general, the latter two patterns of population structures indicate unhealthy or hampered regeneration profiles. 


\section{Discussion}

Generally, species richness, abundance, dominance, frequency and IVI describe the floristic characteristics of an area. The numbers of woody plant species recorded at the study sites (18 at Sherkole and 23 at Kurmuk) are comparable to those reported from Aberegelle, northern Ethiopia (22 spp.; [5]) and Yabello, southern Ethiopia (23 spp.; [12]), where gum- and resin-bearing species are also common.

Figure-2. Diameter class frequency distribution of gum and resin bearing tree species from Kurmuk (diameter class: $1=0-10,2=10-20,3=$ $20-30,4=30-40$ and $5=40 \mathrm{~cm})$

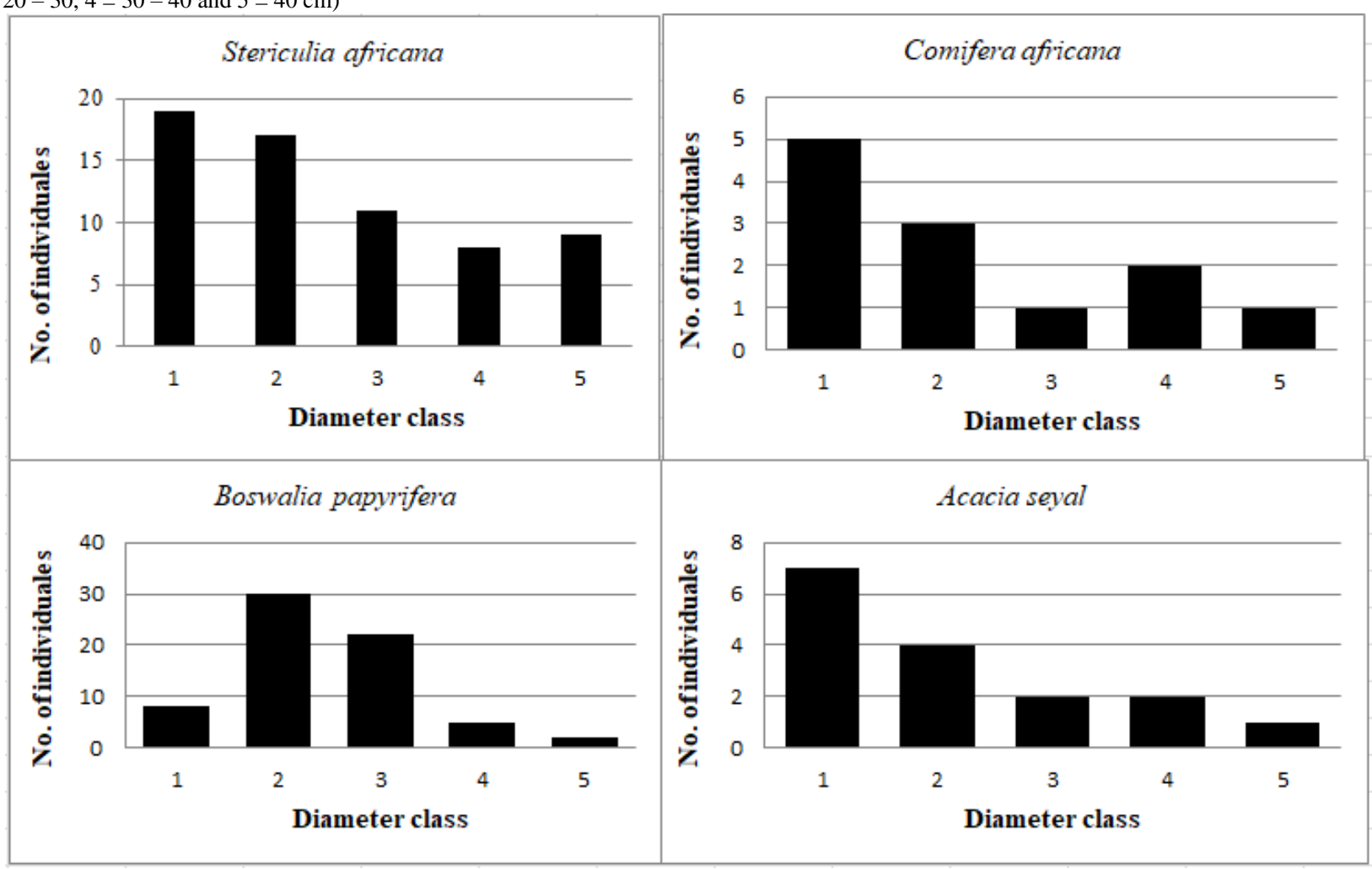

Figure-3. Diameter class frequency distribution of gum and resin bearing tree species from Guba (diameter class: $1=0-10,2=10-20,3=20-$ $30,4=30-40$ and $5=40 \mathrm{~cm})$

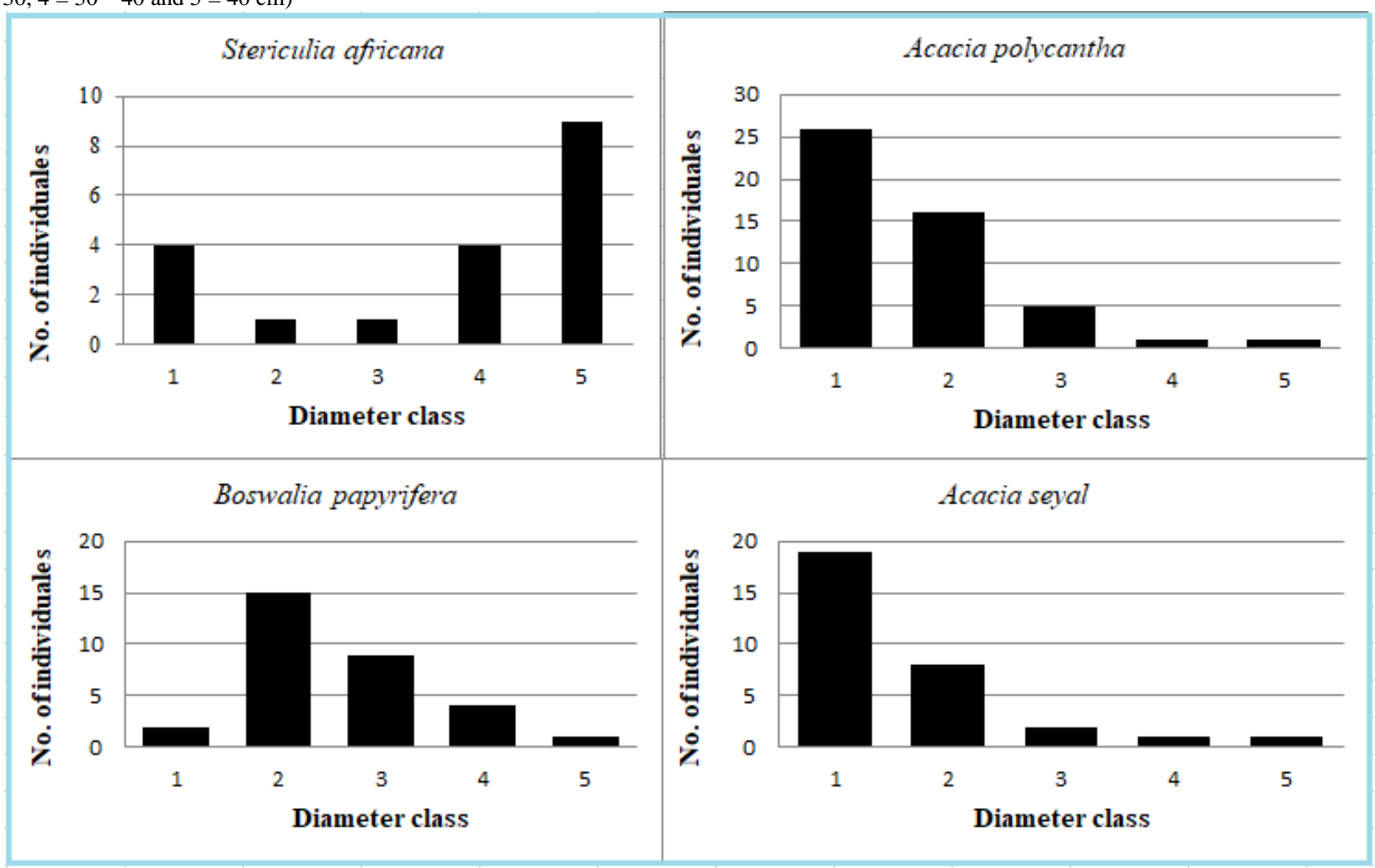

However, the species richness values at the current study sites are far lower than those reported from Combretum-Terminalia forests in Metema, northern Ethiopia (78 spp.; [20]) and Acacia-Commiphora woodlands in Arero, southern Ethiopia (41 spp.; [12]). On the other hand, Sherkole and Guba are relatively floristically richer than 
Upper Rift Valley areas where only six woody species were encountered in the established quadrates [21]. Gebrehiwot [22], also reported fewer species (13 woody spp.) in Boswellia-dominated dry woodlands in selected areas of northern Ethiopia.

In terms of gum- and resin-bearing woody species, BGNRS houses lesser number of species than that of Borana, southern Ethiopia, where 18 gum- and resin-bearing species were reported in the Acacia-Commiphora vegetation even from lesser number of sample plots [12]. Similarly, the Acacia-Commiphora dry forests of South Omo Zone houses 15 gum- and resin-bearing species [11]. Nonetheless, the study sites support a comparable number of gumand resin-bearing woody species to those reported from dry forests/woodlands in northern (nine species), central (two species) and southeastern (seven species) parts of Ethiopia where similar assessment methods were employed $[5,9,21,22]$.

Gum- and resin-bearing species have considerable significance at both study sites based on their density, frequency, dominance and IVI. For instance, at Sherkole, $29 \%$ of B. papyrifera contributes up to $90 \%$ of Ethiopia's annual gum and resin trade volume, implying the great importance of this species. In contrast, existing unhealthy population demography of the species across all its natural growing ranges, including the current study areas, implies that the country at large and rural livelihoods that depend on this species for a considerable proportion of their annual income and the many export companies, in particular, may lose their income in the future. In other words, frankincense production from B. papyrifera may not be sustainable.

S. africana showed different population structures at the two study sites, i.e. stable and hampered regeneration in Kurmuk and Sherkole, respectively. Also, its density is four times higher in Kurmuk than in Sherkole. In Sherkole, a large number of individuals of this species belong to the highest diameter class, i.e. old trees, with very low or no chance of being replaced when they die. This pattern clearly indicates hampered regeneration, which might have been caused by poor seed production of the species due to old age or other environmental problems as well as poor seedling and sapling recruitment, e.g. due to heavy grazing by animals [23]. Informal and formal discussions with key informants revealed that domestic and wild animals browse the seedlings of most gum-and resin- bearing species. Field level observations and discussions with local experts also revealed that Kurmuk is harsher in terms of temperature than Sherkole and, hence, that more people are engaged in livestock production. It is a common practice in the study area, and elsewhere in Ethiopia, to let livestock graze in forests. Local experts also argued that since the district is relatively scarcely populated, there are more wild herbivores. More domestic and wild herbivores in Sherkole than in Kurmuk may, thus, have contributed to the hampered regeneration of some woody species. Local experts also mentioned the prevalence of more soil degradation in Sherkole district. In general, the woody species categorized in the second and third group require special attention to address their hampered regeneration. As mentioned in the introductory part of this article [14], BGNRS has become one of the few regions targeted by government led re-settlement and commercial farming. According to this author, in some areas in the region, there is a growing influx of human and livestock population, adding pressure on the natural landscapes and reproduction of forest trees now and in the future. The key informants also mentioned the increasing negative effects of climate change and variability, and forest fire risks along with deforestation due to land use changes during the past few decades.

Our results revealed that BGNRS is among the regions known to support extensive forest resources dominated by gum- and resin- producing woody species. Our discussions with local people, experts and export companies of gums and resins about the production of gums and resins in the study areas revealed that, unlike the Amhara and Tigray National Regional States, a few export companies are engaged in the production, processing and export of gums and resins in BGNRS. The Natural Gum Processing and Marketing Enterprise, which is the major government parasternal gum and resin export company, and a few private companies out of the over 30 nationally licensed gum and resin export companies produce, process and export, mainly, frankincense but also gum Arabic in BGNRS, including in the study areas. According to local natural resource experts, such a thin representation of major actors from the central marketing system is a serious bottleneck to demonstrate the socio-economic significance of the gum and resin resources in the region. Despite the inadequate number of export companies, Alemu, et al. [24] reported that more than 300 tons of frankincense and gum Arabic, worth 0.6 million USD, were collected, processed and exported in the BGNRS in 2011. This implies the importance of BGNRS for enhancing gum and resin commercialization and, thereby, promoting integrated management of the dry forests rather than changing them to other land uses.

Further, Worku, et al. [12] emphasized that if managed well and integrated with other production systems, existing populations of gum- and resin- producing woody species in the region will offer opportunities for the local communities to access additional incomes. Although not well-organized, the local communities in BGNRS are also engaged in the collection and sale of gums and resins as individuals and, in some areas, co-operatives. The current participation in and benefits of local households from gums and resins would be further enhanced both by establishing new strong co-operatives and strengthening existing ones as well as connecting them with market outlets. As elaborated in various reports (e.g. [12, 25]), organizing the local communities to benefit from the gum and resin trade will enhance ownership and responsible management of the rampantly degrading CombretumTerminalia forest vegetation in this part of Ethiopia.

Further comparatives studies, mainly in areas of regeneration that could be based on dry and wet seasons, exploration of diversity, estimation of gum and resins productivity of the woody species and the overall socioeconomic aspects of the forest resources is needed. There is also a need for research to develop a feasible model that will facilitate strategic integration of dry forests into the current national developmental planning, as an alternative to large scale re-settlements and commercial farming programmes that are proliferating in BGNRS. Research has also 
to develop options to link the gum- and- resin producing forests to the current climate-related funds, such as REDD $\mathrm{p}$ and other opportunities.

\section{Conclusion}

Gum- and resin-bearing woody species, encountered in BGNRS houses lesser number of species than other areas of Ethiopia. Existing unhealthy population demography of the species across all its natural growing ranges, including the current study areas, implies that the country at large and rural livelihoods that depend on this species for a considerable proportion of their annual income and the many export companies, in particular, may lose their income in the future. In other words, frankincense production from B. papyrifera may not be sustainable.

Moreover, large number of individuals of these species belong to the highest diameter class, i.e. old trees, with very low or no chance of being replaced when they die. This pattern clearly indicates hampered regeneration, which might have been caused by poor seed production of the species due to old age or other environmental problems as well as poor seedling and sapling recruitment, e.g. due to heavy grazing by animals.

Further comparatives studies, mainly in areas of regeneration that could be based on dry and wet seasons, exploration of diversity, estimation of gum and resins productivity of the woody species and the overall socioeconomic aspects of the forest resources is needed. There is also a need for research to develop a feasible model that will facilitate strategic integration of dry forests into the current national developmental planning, as an alternative to large scale re-settlements and commercial farming programmes that are proliferating in BGNRS. Research has also to develop options to link the gum- and- resin producing forests to the current climate-related funds, such as REDD $\mathrm{p}$ and other opportunities.

\section{Acknowledgements}

We are grateful to the regional experts, the local administration and people who supported and facilitated the field data collection. We would like to thank the Forestry Research Center for the financial and facility support. We also acknowledge gratefully the anonymous reviewer for the valuable comments on an earlier version of this article.

\section{Disclosure Statement}

No potential conflict of interest was reported by the authors.

\section{References}

[1] Woody Biomass Inventory and Strategic Planning Project WBISPP, 2005. Forest resources of Ethiopia. Addis Ababa: Ministry of Agriculture and Rural Development.

[2] FAO, 2010. Guideline on sustainable forest management in drylands of Sub-Saharan Africa. Arid Zone Forest and Forestry Working Paper No. 1. Rome: FAO.

[3] Friis, I., Demissew, S., and Breugel, P., 2010. Atlas of the potential vegetation of Ethiopia. Copenhagen: The Royal Danish Academy of Sciences and Letters.

[4] Lemenih, M. and Kassa, H. E., 2011. Opportunities and challenges for sustainable production and marketing of gums and resins in Ethiopia. Bogor: CIFOR.

[5] Eshete, A., ., Sterck, F., and Bongers, F., 2011. "Diversity and production of Ethiopian dry woodlands explained by climate- and soil-stress gradients." Forest Ecol. Manage., vol. 261, pp. 1499-1509.

[6] Groenendijk, P., Eshete, A., and Sterck, F. J., 2012. "Limitations to sustainable frankincense production: blocked regeneration, high adult mortality and declining populations." J. Appl. Ecol., vol. 49, pp. 164-173.

[7] Awas, T., 2007. Plant diversity in Western Ethiopia: ecology, ethno-botany and conservation PhD thesis. Oslo: University of Oslo.

[8] Teketay, D., 2004-2005. "Causes and consequences of dryland forest degradation in Sub-Saharan Africa." Walia, vol. 24, pp. 3-20.

[9] Lemenih, M., Abebe, T., and Olsson, M., 2003. "Gum and Resin resources from some Acacia, Boswellia, and Commiphora species and their economic contributions in Liban." South-East Ethiopia. J. Arid. Environ., vol. 55, pp. 465-482.

[10] Worku, A., Lemenih, M., Fetene, M., and Teketay, D., 2011. Socio-economic importance of gum and resin resources in the dry woodlands of Borana vol. 20. Southern Ethiopia: Forests Trees Livelihoods. pp. 137156.

[11] Adem, M., Worku, A., Lemenih, M., Tadesse, W., and Pretzsch, J., 2014. "Diversity, regeneration status and population structure of gum- and resin-bearing woody species in south omo zone." Southern Ethiopia. J. Forestry Res., vol. 25, pp. 319-328.

[12] Worku, A., Teketay, D., Lemenih, M., and Fetene, M., 2012. "Diversity, regeneration status, and population structures of gum- and resin-producing woody species in Borana, Southern Ethiopia." J. Forests Trees Livelihoods iFirst article, pp. 1-12.

[13] Lemenih, M. and Bongers, F., 2011. Dry forests of Ethiopia and their silviculture. In: Günter S, Weber M, Stimm B, Mosandi R, editors. Silviculture in the Tropics, Tropical Forestry. Berlin Heidelberg: SpringerVerlag.

[14] Rahmato, D., 2011. Land to investor: large-scale land transfers in Ethiopia. Addis Ababa: Forum for Social Studies.

[15] Central Statistics Agency CSA, 2007. Population and housing census report. Addis Ababa: Ethiopia. 
[16] Kent, M. and Coker, P., 1992. Vegetation description and analysis: a practical approach. London: John Wiley and Sons.

[17] Peters, M., 1996. The ecology and management of non-timber forest resources. World Bank Technical Paper 322. Washington, DC: World Bank.

[18] Teketay, D., 1997. "Seedling populations and regeneration of woody species in dry Afromontane forests of Ethiopia." Forest Ecol. Manage, vol. 98, pp. 149-165.

[19] Ogbazghi, W., Rijkers, T., Wessel, M., and Bongers, F., 2006. "The distribution of the frankincense tree Boswelliapapyrifera in Eritrea: the role of environment and land use." J. Biogeography, vol. 33, pp. 524535.

[20] Adamu, A., Bekele, T., and Dalle, G., 2012. "Floristic diversity, regeneration status, and vegetation structure of woodlands in metema area, Amhara National Regional State." Northwestern Ethiopia. J. Forestry Res., vol. 23, pp. 391-398.

[21] Argaw, M., Teketay, D., and Olsson, M., 1999. "Soil seed flora, germination and regeneration pattern of woody species in an Acacia woodland of the Rift Valley in Ethiopia." J. Arid. Environ., vol. 43, pp. 411435.

[22] Gebrehiwot, K., 2003. Ecology and regeneration of Boswelliapapyrifera in dry forest of Tigray. North Ethiopia: Go"ttingen: Georg-August University.

[23] Teketay, D., Lemenih, M., Bekele, T., Yemshaw, Y., Feleke, F., Tadesse, W., Moges, Y., Hunde, T., and Nigussie, D., 2010. Forest resources and challenges of sustainable forest management and conservation in Ethiopia. In: Bongers F, Tennigkeit T, editors. Degraded forests in Eastern Africa: management and restoration. London: Earthscan.

[24] Alemu, A., Eshetu, Z., Garedew, E., and Kassa, H., 2015. "Assessment of vegetation characteristics and production of boswelliapapyrifera woodlands in north western lowlands of Ethiopia." Sky J. Agric. Res., vol. 4, pp. 008-013.

[25] Woldeamanuel, T., 2011. Dryland resources, livelihoods and institutions diversity and dynamics in use and management of gum and resin trees in Ethiopia. PhD thesis. The Netherlands: Wageningen University. 